\title{
A NEW ADAPTOR WHICH OBVIATES PROBLEMS ASSOCIATED WITH CONDOM EXTERNAL URINARY DRAINAGE OF MALE PATIENTS
}

By J. W. Pearman, M.B., B.S., and S. K. Shah, O.T.D., C.R.; O.T.R. (U.S.A.)

Department of Microbiology and The Spinal Unit, Royal Perth Hospital, Perth

Western Australia and Department of Therapy, Western Australian

Institute of Technology, Perth, Western Australia

\section{INTRODUCTION}

RUBBER urinals worn by male patients who are incontinent following spinal cord injury or paralysis are unsatisfactory for many patients because the rubber sheath causes repeated ulceration of the penile skin necessitating confinement to bed until the lesions heal. The straps and buckles often break down the skin on the abdomen and thighs. Moreover, many spinal cord injured patients take a long time to put on a rubber urinal because of difficulty in securing the straps and buckles (fig. I).

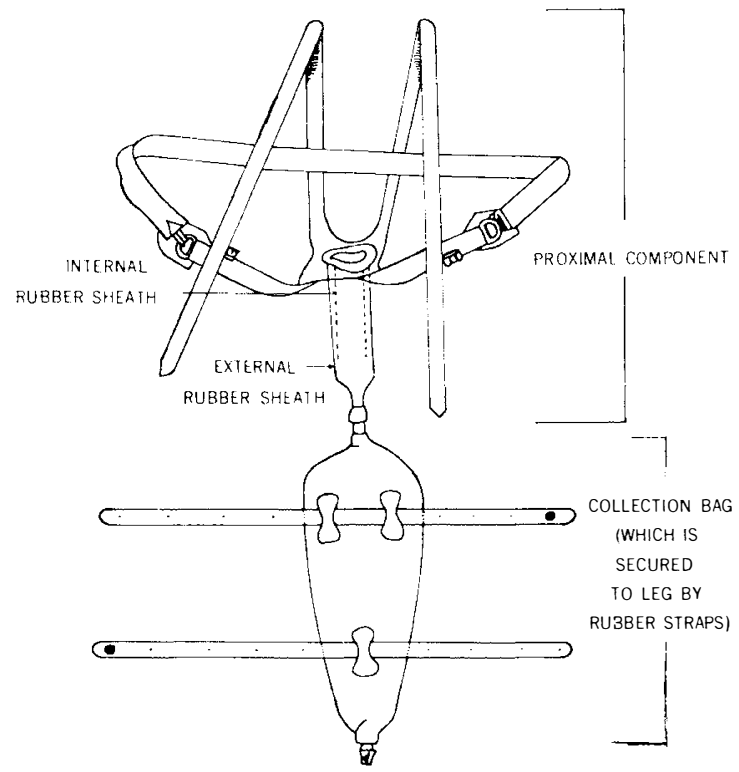

FIG. I

Diagram of a conventional rubber urinal.

Several patients with complete cervical cord lesions were observed. On average they took approximately 50 minutes to apply the proximal component of the rubber urinal and they all needed some assistance. These patients frequently abraded the genital skin during self-application (i.e. the proximal component of the rubber urinal was non-functional in terms of independent application by tetraplegics). 
Due to the skin problems and the inability of tetraplegics to attain independence with the rubber urinal it was decided to use condom external urinary drainage for male patients (figs. $2 \mathrm{~A}, \mathrm{~B}$ ). Condom drainage virtually eliminated the occurrence of penile skin ulceration and its application was comparatively simple compared with the proximal component of the rubber urinal. Some of the tetraplegics who were unable to put the inner sheath of the rubber urinal over the penis were able

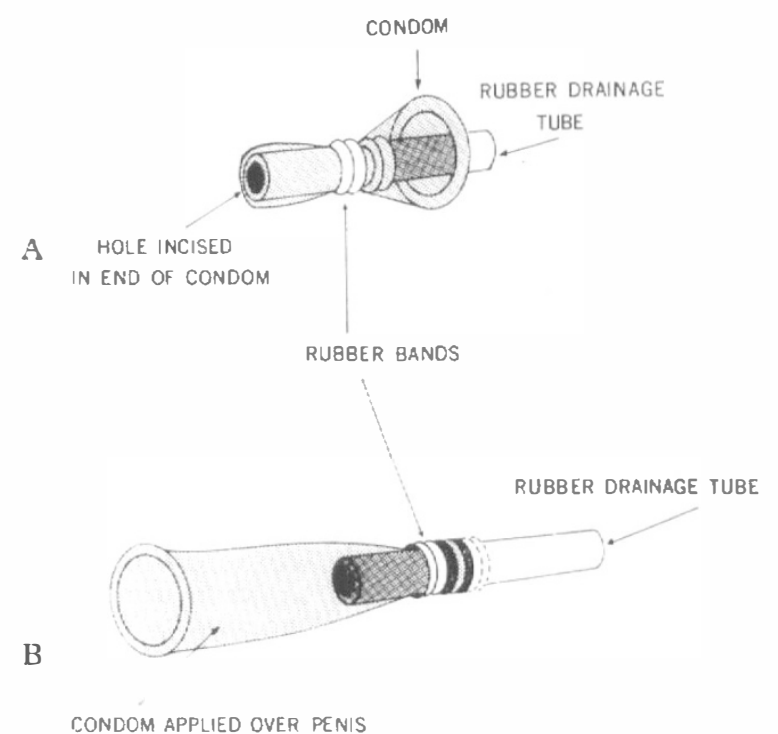

FIGs. 2A and B.

Condom secured to drainage tube by means of rubber bands.

to roll the condom on to the penis. However, four problems were encountered with this apparatus:

I. The diameter of the tube was insufficient to take the flow of urine from some patients; particularly those with upper motor neurone (reflex) bladders.

2. During daily activities the drainage tube rotated, thereby twisting the condom so that it became obstructed.

3. Urine tended to remain between the rubber drainage tube and the lower end of the condom. Failure to drain the condom completely led to maceration of the skin over the distal end of the penis in some patients.

4. Tetraplegic patients were unable to apply the rubber band over the drainage tube to fasten the condom in place (figs. $2 \mathrm{~A}$ and $\mathrm{B}$ ).

\section{THE NEW CONDOM ADAPTOR}

A funnel-shaped adaptor was designed to overcome these problems (fig. 3). It is made of polypropylene so that it can be autoclaved or boiled after each day's use. A high urine flow rate can be accepted by the adaptor due to its internal diameter of $\frac{3}{8}$ inch $(0.95 \mathrm{~cm}$.) To prevent the rapid flow of urine being impeded 
the internal angle between the funnel and the tubular section is rounded-off. The expanded proximal end, which has an external diameter of $\mathrm{I} \cdot 05$ inches $(2 \cdot 7$ $\mathrm{cm}$.), holds the condom wide open thus preventing its obstruction when twisted by rotation of the drainage tube. The funnel's shape ensures that the condom

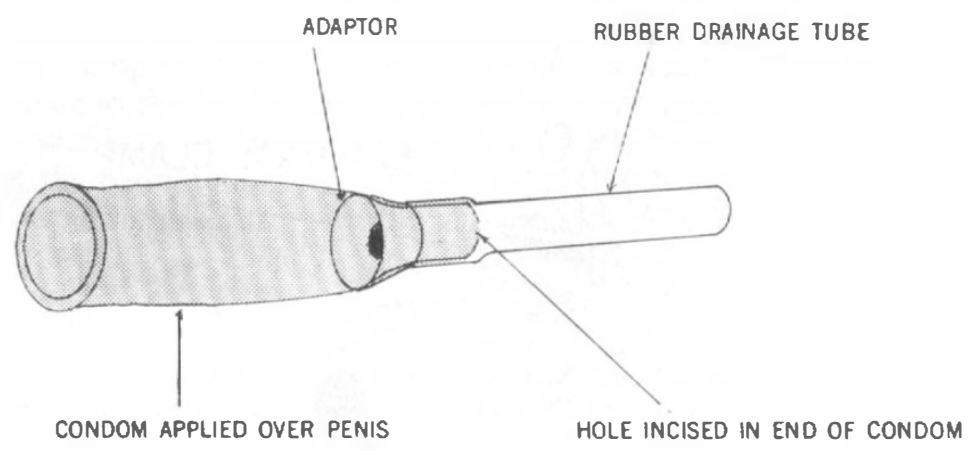

FIG. 3

Funnel-shaped adaptor.

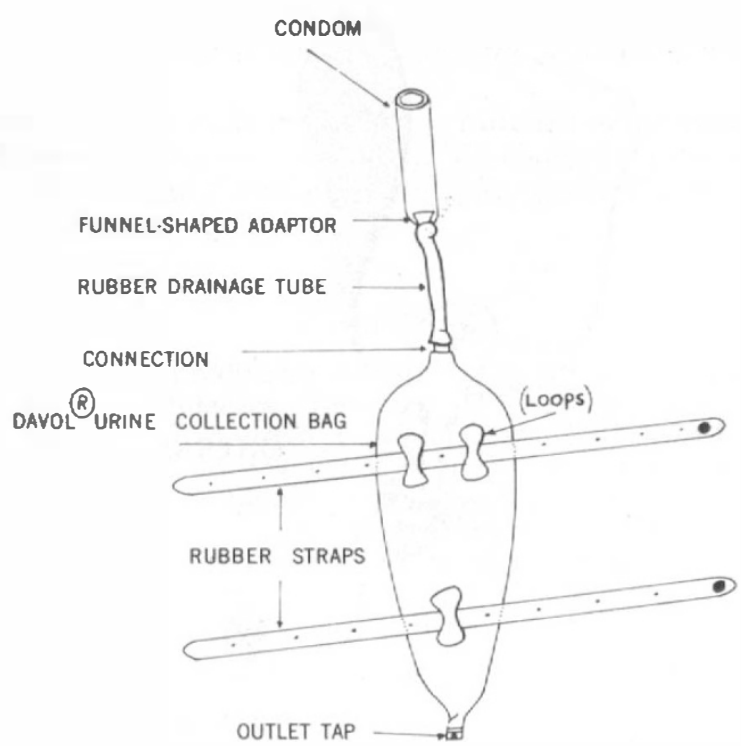

FIG. 4

Condom connected to Davol® urine collection bag.

is stretched tightly over its external surface so that no urine remains between the condom and the adaptor. Tetraplegics using wrist-driven prehension orthosis, or those with satisfactory natural tenodesis action resulting from appropriate tightness of the long flexors of the fingers, can put on this device independently. Skin-Bond ${ }^{\circledR}$ cement is painted around the penis before the condom is rolled on. 


\section{ADDITIONAL EQUIPMENT}

The rubber drainage tube, which usually needs to be approximately 5 inches $\left(12.7 \mathrm{~cm}\right.$.) in length, is connected to a Davol ${ }^{\circledR}$ collection bag, size 19 , attached to the leg by two rubber straps threaded through loops on the side of the bag (Fig. 4).
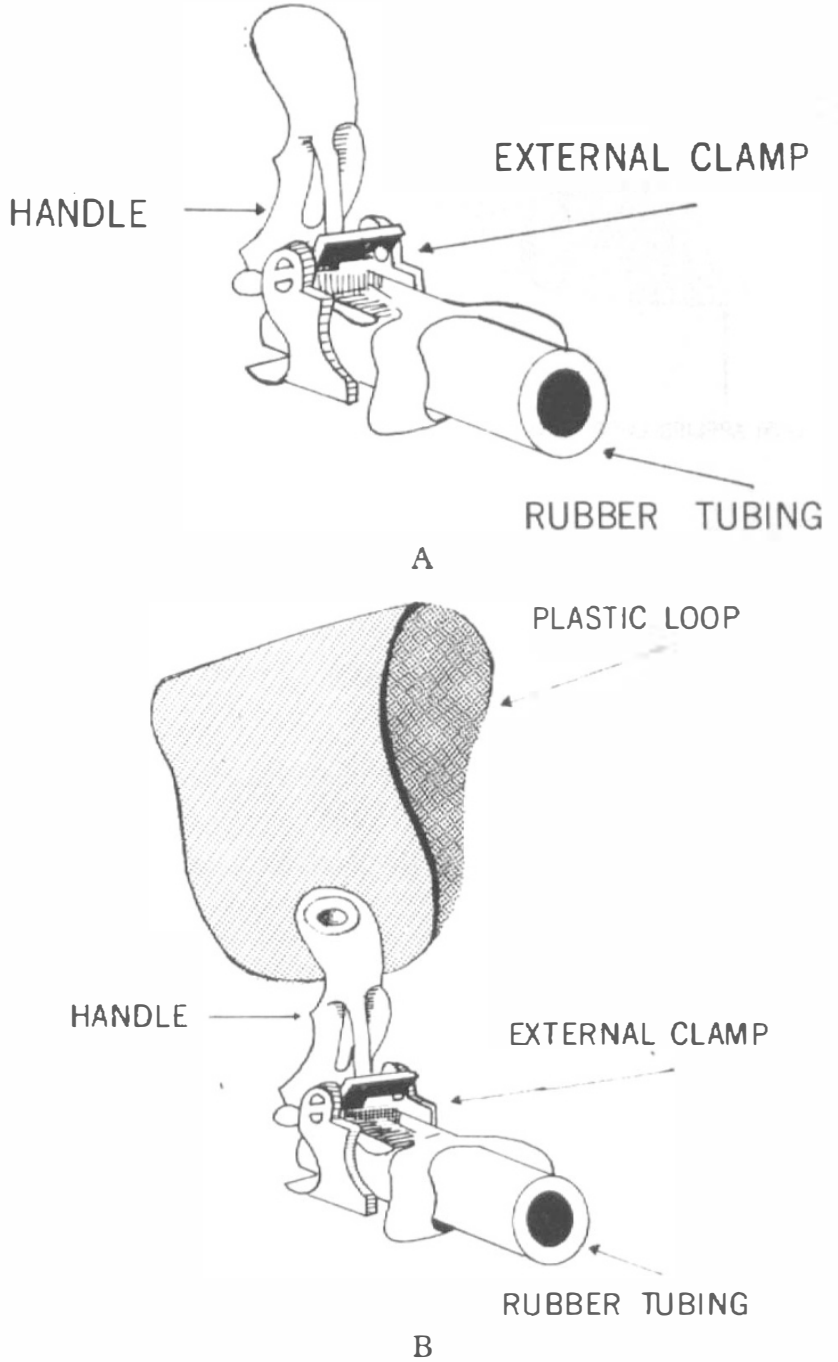

FIG. 5

A, Outlet tubing and clamp for patients who cannot operate a screw tap. B, Modified outlet clamp which can be operated by some tetraplegics.

A screw-on connection ${ }^{1}$ of $\frac{3}{8}$ inch $(0.95 \mathrm{~cm}$.) internal diameter is necessary to join the drainage tube to the collection bag (fig. 4). If this internal measurement

${ }^{1}$ Manufactured by Polyplastics Pty. Ltd., Perth, Western Australia. 
is less than those of the funnel-shaped adaptor ${ }^{1}$ obstruction to flow may occur. This connection should be made of polyoxymethylene so that a calcified deposit is not accumulated and it can be autoclaved or boiled.

An alternative outlet for the collection bag is available for those patients unable to operate the outlet tap at the bottom of the bag (fig. 4). The outlet tap is replaced by a short length of rubber tubing to which is applied an external clamp which can be clamped or released by pressure of a hand (fig. 5A). Modifications have been made to the handle enabling it to be easily operated by patients with no voluntary power in their hands. A plastic loop has been attached to the end and the curve of the handle has been increased (fig.5B) thus permitting the patient to move it by applying pressure with the vasco-elastic resistance of the thumb.

\section{SUMMARY}

When worn by patients with spinal cord lesions conventional rubber urinals often produce ulceration of the penile skin. Many male tetraplegics who are unable to put on the proximal component of a rubber urinal without assistance are able to apply a condom, i.e. they are able to achieve increased independence by using condom external urinary drainage. A new adaptor obviating the problems associated with this form of urinary drainage is described. It has an internal diameter which accepts a high urine flow rate and is expanded at its proximal end to hold open the condom so that it does not become obstructed when twisted.

Acknowledgements. We are indebted to Mr. J. Mitchell of the Educational Development Unit of the Western Australian Institute of Technology for preparing the illustrations and to Mr. K. M. Hartz of Polyplastics Pty. Ltd., Perth, Western Australia, for his help in developing this piece of equipment.

\section{RÉSUMÉ}

Les urinaux en caoutchouc produisent souvent des ulcérations de la peau du pénis chez les malades avec des lésions médullaires. Beaucoup de tétraplégiques mâles sont incapables de se mettre la partie proximale d'un urinal en caoutchouc sans assistance mais sont capables par ailleurs, de mettre un urinal du type condome, ce qui accroit leur indépendance. Un nouvel adaptateur, qui évite les problèmes associés avec ces formes de drainage urinaires, est décrit. Il a un diamètre interne qui est compatible avec un débit urinaire élevé et est élargi à son bout proximal, de façon à maintenir ouvert le condome, èvitant ainsi l'obstruction lors de la torsion de ce dernier.

\section{ZUSAMMENFASSUNG}

Ein neuer Adaptor für aüssere Kondom-Drainage von Urin wird beschrieben, welcher gewisse Nachteile der üblichen Gummi-urinale ausschliesst. Er ist mit einem Diameter ausgestattet, der einen hohen Grad von Urinstrom erlaubt und durch seine Erweiterung seines proximalen Endes den Kondom offen hält und dadurch Obstruktion vermeidet.

\footnotetext{
${ }^{1}$ Manufactured by Polyplastics Pty. Ltd., Perth, Western Australia.
} 